\title{
商用周波交流による電氣スクリーンの性能について
}

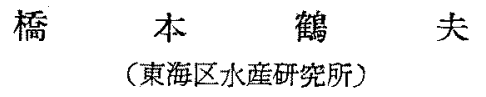

\section{An Experiment on the Performance of an Electric Fish Screen}

\section{Tsuruo Hashimoto}

To obtain necessary data for designing an electric fish screen more efficient than those tested previously, effect of electric current on fish has been studied along with field tests on the performance of an experimental screen.

1) Effect of electric current of fish:- Electric potential gradient to which fish would react was measured when the current ran in parallel or came at right angles with the body of fish. Critical potential gradient to paralyze a fish was also investigated. The results of the experiments. are given in Table 1 and Figure 3.

2) Field test on the performance of an experimental screen:- From a practical point of view a vertical grid type of electric screen was employed to supply an alternating current of 50 or 60 cycles respectively. The screen, as illustrated in Figure 1, consisted of a series of vertical grids of copper wire hung from the feeders spanned across a stream leading to a fish farm. It was arranged in accordance with Tauti's theories (1932) so that distribution of the electric potential in the fields between the consecutive grids or electrodes was intensified just as the fish swam ahead by adjusting distance between the poles or using different voltage of the current.

Two sets of the screen were installed across the water way, dividing it into three sections $A, B$ and $C$, as illustrated in Figure 4. A net made of wire or thread to be placed at the ends of the section will serve to keep the fish inside. Keep a similar net between the sections until the fish get calm down in the section B, and when counting the fish fled into sections $A$ and $\mathrm{C}$.

Release a certain number of fish in section $B$, then start the operation to observe effect of the electric current upon behaviors of the fish, taking the net partitions out of the water.

Because of difficulty in counting the number of fish driven back by the screen, the screening efficiency was expressd in a ratio computed as

$$
\frac{\mathrm{N}-\mathrm{N} f-\mathrm{N} e}{\mathrm{~N}}
$$

where $N$ represents the number of fish, $N f$ the number of fish fled through the sereen, and $N e$ the fish electrocuted. Table 2 indicates the results thus obtained with detail of the experimental cenditions.

Since the potential gradient was distributed as shown in Figure 2, the fish, when they swam in group, would turn back just before reaching the first grid or the second. Even when happened to pass through the first, they would soon come back and remain swimming about in 
a safe area of B where little or no electric potential gradient existed. However, when a fish swam independently from the group, it often rushed into the fields inside of the grids to be benumbed, or in the worst, electrocuted. Small sized fish or youngs, especially those reared in a hatchery, were found difficult to be screened away by the electric current.

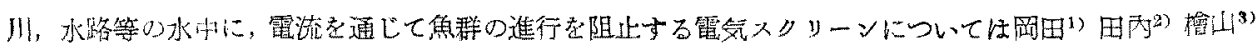

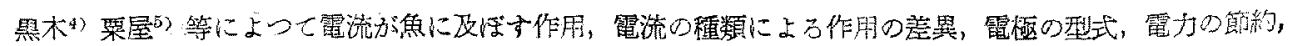
阻止率等㟟喽的な研究が発表せられている。

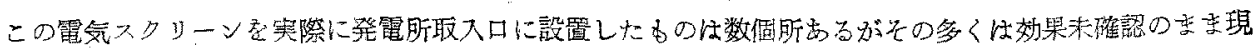

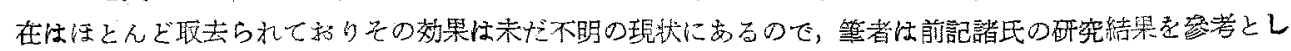

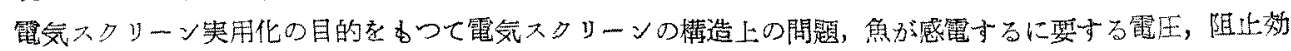

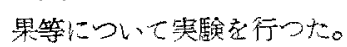

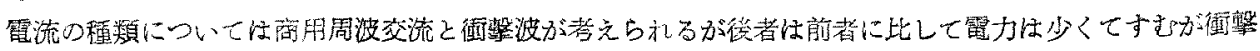

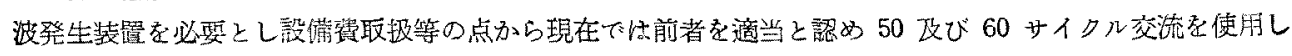
たo

\section{1 露気スクリーンの構造}

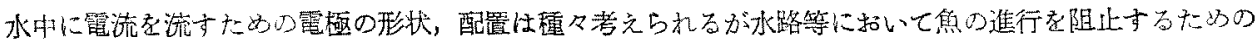

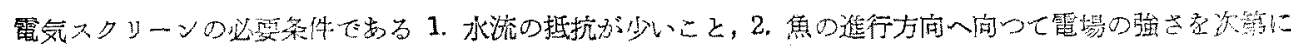

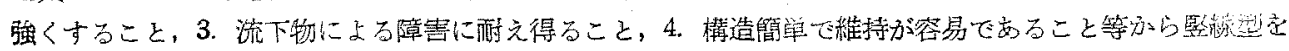

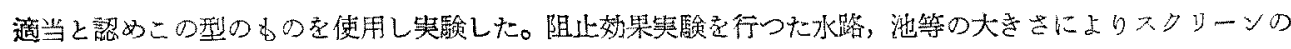

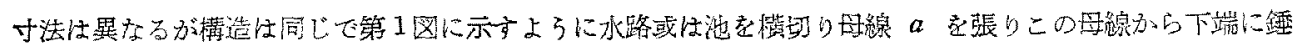
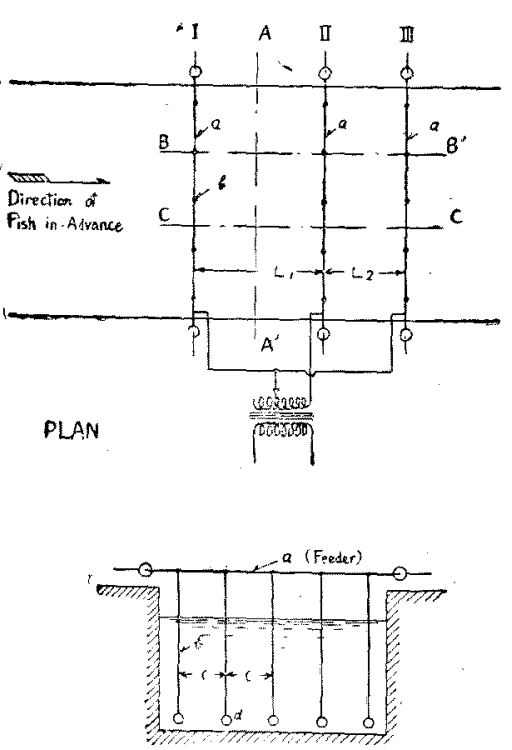

SECTION \& A-A

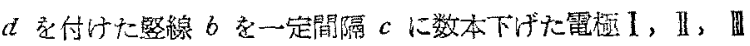

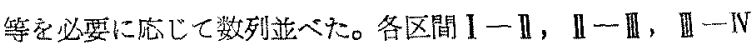

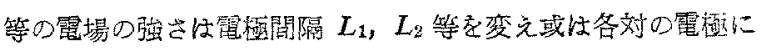
加える雪仕变えて魚の進大方向に向つて次第に強くなるよら にした。

電極として水中にある豎舶の面頭が水路の横断面䅡に比し

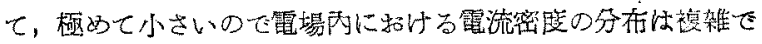

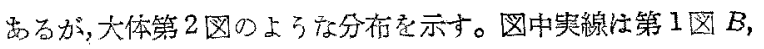

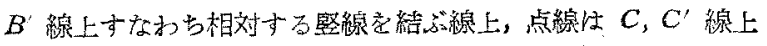
寸なわち上記の閒の線上の各部分でいずれすこれ的の綜の力间

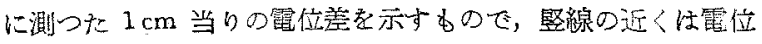

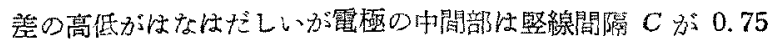

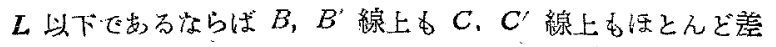

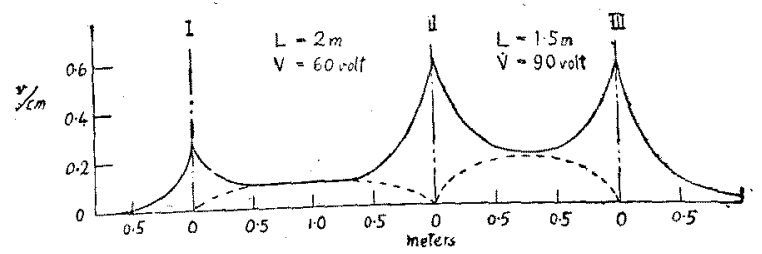

Fig. 2. Distribution of Potential Gradient.

Fig. 1. Arrangement of electric Screen. 


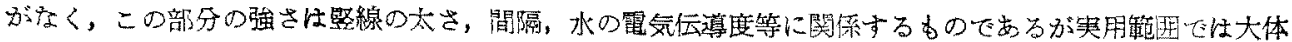

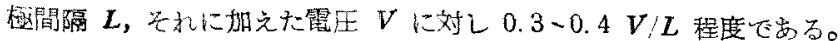

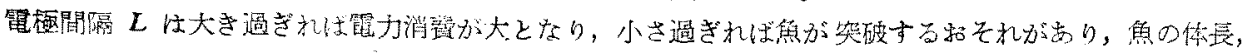

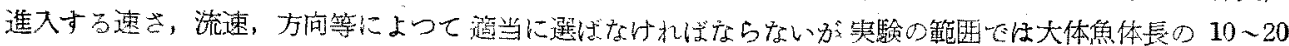
倍程度方过造当と誌められた。

\section{1 魚が感電するに要する雷压}

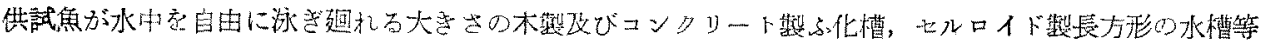

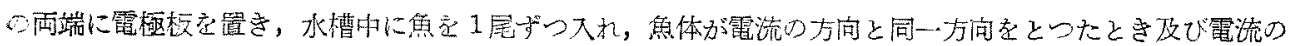

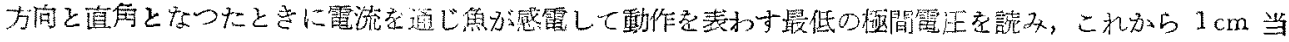

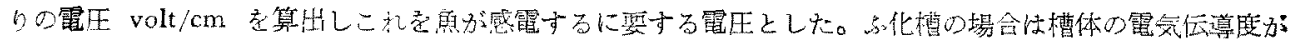

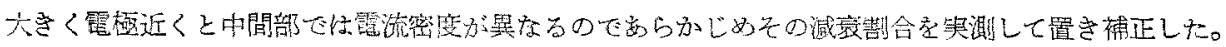

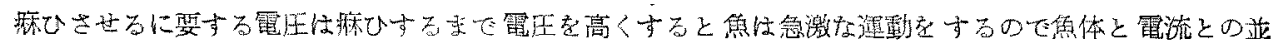

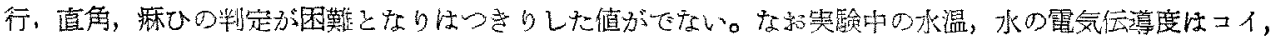

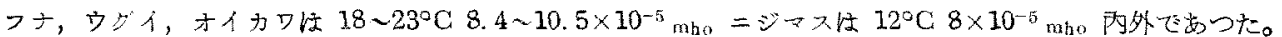

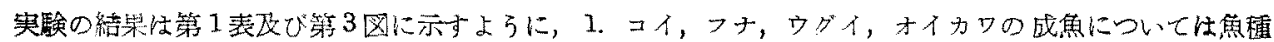

Table 1. Effect of Electric Current (A. C) on fish.

\begin{tabular}{|c|c|c|c|c|}
\hline \multirow{3}{*}{ Species } & \multirow{3}{*}{$\begin{array}{r}\text { Body Length } \\
\mathrm{cm}\end{array}$} & \multicolumn{3}{|c|}{ Potential Gradient volt $/ \mathrm{cm}$} \\
\hline & & \multicolumn{2}{|c|}{ First sign of electric sohck } & \multirow[b]{2}{*}{ Paralyzing } \\
\hline & & $\begin{array}{l}\text { Parallel with } \\
\text { the Current }\end{array}$ & $\begin{array}{l}\text { Across the } \\
\text { Current }\end{array}$ & \\
\hline \multirow{10}{*}{ Carp } & 19.0 & 0.042 & 0.096 & \\
\hline & 17.0 & 0.055 & 0.112 & \\
\hline & 14.5 & 0.047 & 0.083 & \\
\hline & 13.2 & 0.056 & 0.102 & \\
\hline & 13.0 & 0.047 & 0.142 & \\
\hline & 12.5 & 0.046 & 0.084 & \\
\hline & 12.5 & 0.060 & 0.119 & \\
\hline & 12.0 & 0.057 & 0.113 & \\
\hline & 11.0 & 0.045 & 0.145 & \\
\hline & 11.0 & 0.036 & 0.081 & \\
\hline \multirow{8}{*}{ 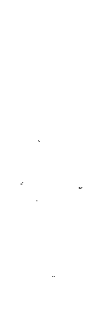 } & 10.5 & 0.045 & 0.109 & \\
\hline & 10.5 & 0.045 & 0.125 & \\
\hline & 10.5 & 0.065 & 0.131 & \\
\hline & 9.0 & 0.056 & 0.122 & \\
\hline & 9.0 & $0 \cdot 057$ & 0.162 & \\
\hline & 8.5 & 0.052 & 0.132 & \\
\hline & 8.5 & 0.056 & 0.141 & \\
\hline & $7: 5$ & 0.065 & 0.151 & \\
\hline & 2.00 & 0.027 & 0.062 & \\
\hline & 19.5 & 0.032 & 0.072 & \\
\hline & 19.5 & 0.032 & 0.082 & \\
\hline & 18.5 & 0.037 & 0.082 & \\
\hline
\end{tabular}




\begin{tabular}{|c|c|c|c|c|}
\hline \multirow{16}{*}{ Crurian carp } & 18.5 & $0 .(3)$ & 0.072 & \\
\hline & 11.5 & 0.042 & 0.122 & \\
\hline & 11.5 & 0.057 & 0.116 & \\
\hline & 11.0 & 0.055 & 0.150 & 0.500 \\
\hline & 10.5 & 0.066 & 0.350 & \\
\hline & 10.2 & 0.063 & $0.1 \varepsilon 4$ & \\
\hline & 10.0 & 0.063 & 0.234 & 0.667 \\
\hline & 8.5 & 0.063 & 0.155 & \\
\hline & 8.0 & 0.065 & 0.174 & \\
\hline & 8.0 & 0.057 & 0.169 & \\
\hline & 7.7 & 0.072 & 0.117 & \\
\hline & 7.5 & 0.067 & 0.200 & 0.583 \\
\hline & 7.5 & 0.061 & 0.200 & 0.933 \\
\hline & 7.3 & 0.064 & 0.157 & \\
\hline & 6.5 & 0.055 & 0.147 & 0.866 \\
\hline & 4.2 & 0.080 & 0,234 & 0.666 \\
\hline \multirow{20}{*}{$\begin{array}{l}\text { Common dace } \\
\text { (Tribolodon } \\
\text { bakuensis) }\end{array}$} & 22.0 & 0.037 & 0.085 & \\
\hline & 20.5 & 0.037 & 0.077 & \\
\hline & 20.5 & 0.043 & 0.133 & 0.234 \\
\hline & 20.0 & 0.039 & 0.083 & \\
\hline & 19.0 & 0.037 & 0.094 & \\
\hline & 19.0 & 0.043 & 0.100 & 0.334 \\
\hline & 18.0 & 0.047 & 0.115 & \\
\hline & 18.0 & 0.037 & 0.110 & 0.234 \\
\hline & 16.8 & 0.037 & 0.094 & \\
\hline & 16.0 & 0.050 & 0.130 & 0.266 \\
\hline & 14.5 & 0.050 & 0.100 & 0.284 \\
\hline & 13.5 & 0.041 & 0.095 & \\
\hline & 12.0 & 0.047 & 0.164 & \\
\hline & 12.0 & 0.047 & 0.146 & \\
\hline & 11.5 & 0.048 & 0.137 & \\
\hline & 11.0 & 0.048 & 0.120 & \\
\hline & 7.0 & 0.070 & 0.234 & 0.530 \\
\hline & 6.5 & 0.083 & 0.234 & 0.600 \\
\hline & 6.5 & 0.077 & 0.300 & 0.500 \\
\hline & 6.0 & 0.073 & 0.216 & 0.500 \\
\hline \multirow{7}{*}{$\begin{array}{c}\text { Minnow } \\
\text { (Zacco platypus) }\end{array}$} & 9.0 & 0.063 & 0.158 & 0.367 \\
\hline & 8.0 & 0.062 & 0.178 & 0.400 \\
\hline & 7.5 & 0.063 & 0.150 & 0.400 \\
\hline & 7.5 & 0.057 & 0.150 & 0.367 \\
\hline & 7.0 & 0.047 & 0.147 & 0.600 \\
\hline & 6.5 & 0.050 & 0.150 & 0.333 \\
\hline & 3.4 & 0.167 & 0.433 & 1. 100 \\
\hline
\end{tabular}




\begin{tabular}{|c|c|c|c|c|}
\hline \multirow{9}{*}{ Young carp } & 3.2 & 0.127 & 0.500 & 1. 270 \\
\hline & 3.0 & 0.150 & 0.566 & 1. 270 \\
\hline & 3.0 & 0.143 & 0.600 & 1.270 \\
\hline & 3. 0 & 0.147 & 0.670 & 1. 130 \\
\hline & 3.0 & 0.153 & 0.630 & 1. 333 \\
\hline & 2.8 & 0.137 & 0.670 & 1. 130 \\
\hline & 2.8 & 0.124 & 0.600 & 1. 130 \\
\hline & 2.8 & 0.157 & 0.633 & 1. 100 \\
\hline & 2.6 & 0.180 & $0 . € 34$ & 1. 330 \\
\hline \multirow{10}{*}{$\begin{array}{l}\text { Rairbow } \\
\text { Trout }\end{array}$} & 16.0 & 0.013 & 0.045 & 0.108 \\
\hline & 15,5 & 0.013 & 0.050 & 0.108 \\
\hline & 14.5 & 0.017 & 0.054 & 0.200 \\
\hline & 12.5 & 0.019 & & \\
\hline & 10.5 & 0.013 & 0.050 & \\
\hline & 9.0 & 0.025 & & \\
\hline & 9.0 & 0.016 & 0.068 & 0.109 \\
\hline & 8.5 & 0.023 & 0.057 & \\
\hline & 8.5 & 0.016 & & \\
\hline & 8.5 & 0.014 & 0.045 & 0.144 \\
\hline
\end{tabular}

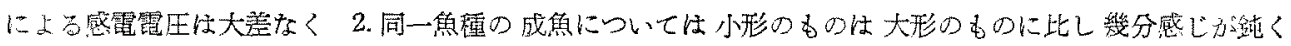

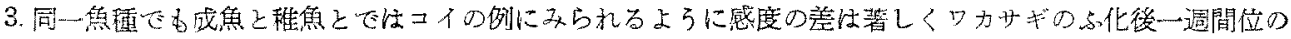
もの忙 1 volt $/ \mathrm{cm}$ 以上の強さでないと感じない４.魚体が電流を直角の場合々並行の場合に比し $2 \sim 3$ 倍の

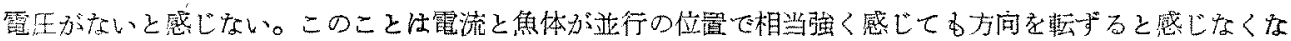

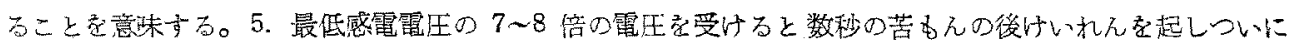
呼吸を停止するが数分以內に電流老断つと回復し容易に死风ことはない。

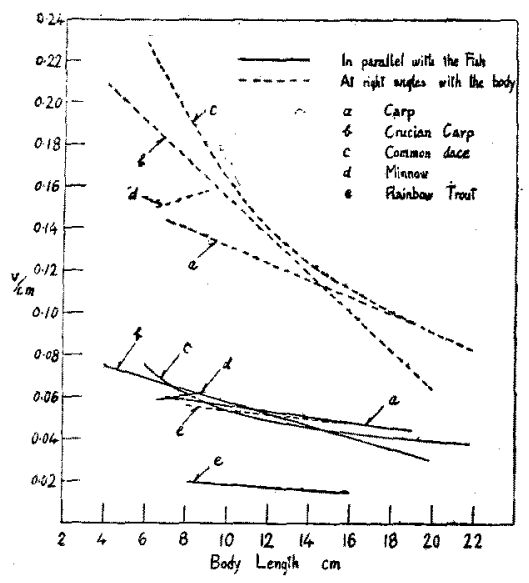

Fig. 3. Potential Gradient for Electric Shock.

\section{III 阻 止 効 果}

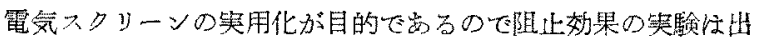

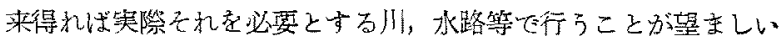

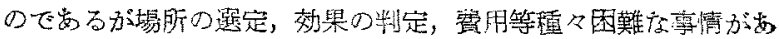

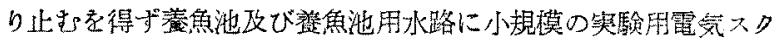

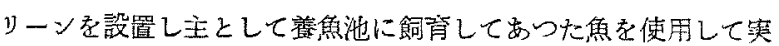

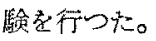

コイ、フナ,ウグイ、アュについては淡水区水産䂜究所上田支 所の水路学 4 図の上万に金網に仕切つて三区分し上，下流に各

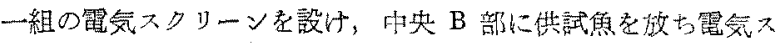
クリーント電流を通じ仕切網 $b, b^{\prime}$ を取り除き $\mathrm{B}$ 部の魚が電場 を通過して A 或は $\mathrm{C}$ 部に進大した数を調へ， B 部に残つたを す

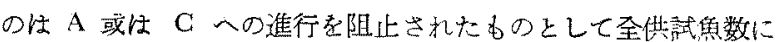

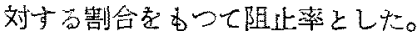

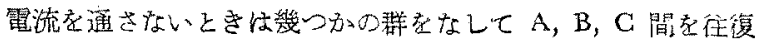
して呿り，水の清濁によつて多少差はするが C 部が他より幾らか梁くなつているのでこへ多く集立る傾 


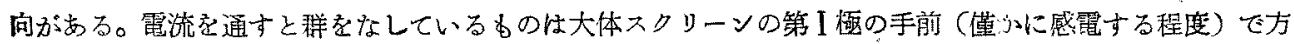

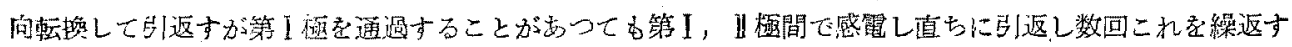

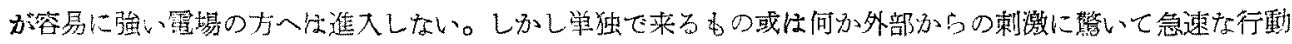

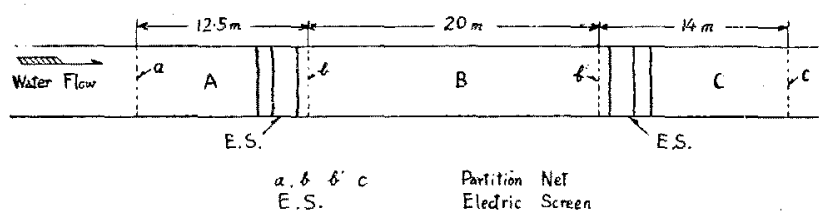

Fig. 4. Arrangement for Field Test.

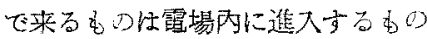
が多く、ここで強く感電して医るも のむあるが，方向老笑つて趋回しい つより強い筹11，四極の力八淮为， ひいにスタリーン就通してしはら

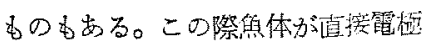

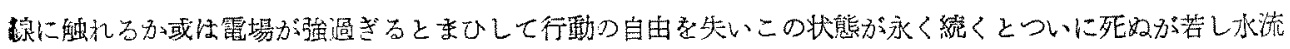
のために押流され電埸外へ出ると閒もなく回復する。

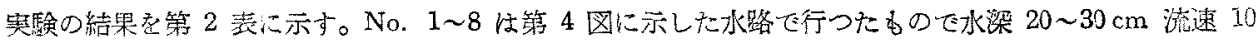

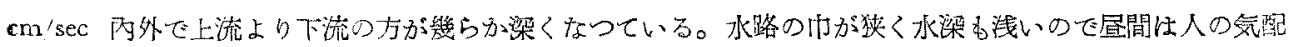

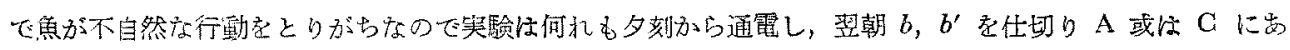

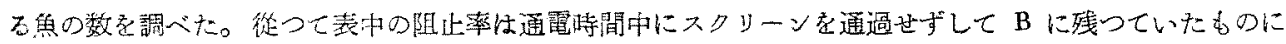

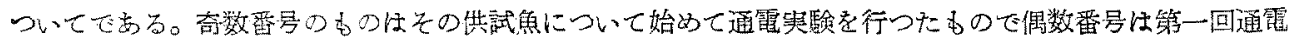

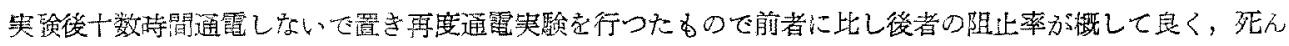

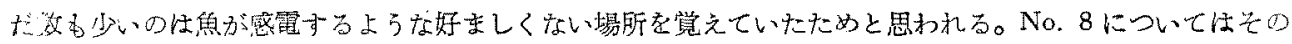

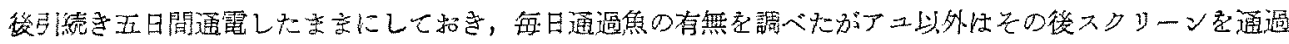

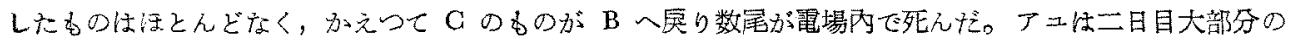

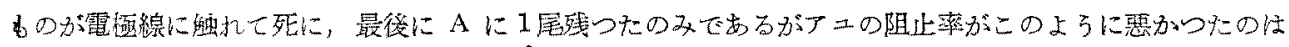

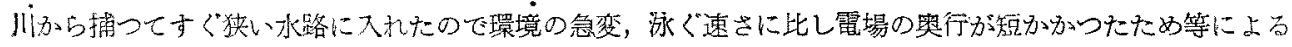

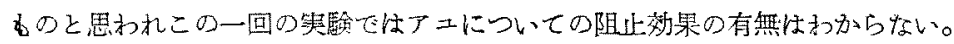

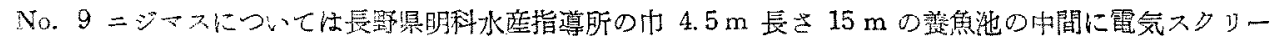

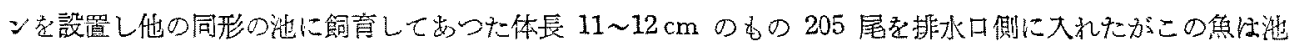

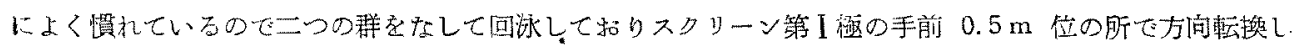

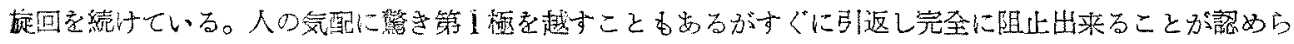
れた。

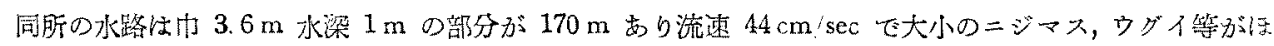

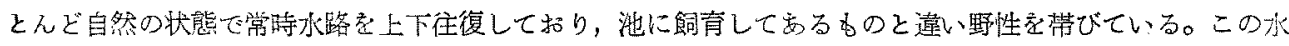

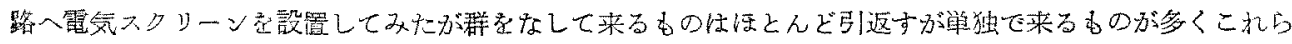

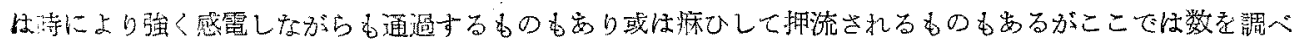

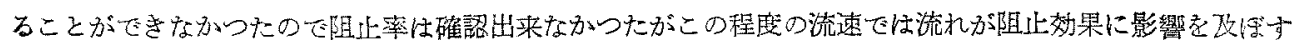

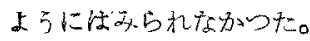

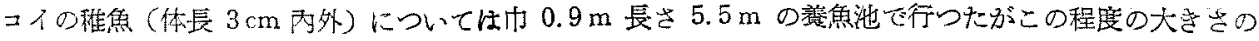

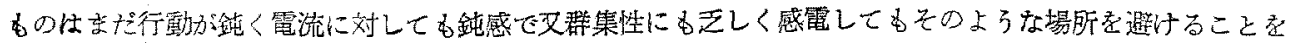

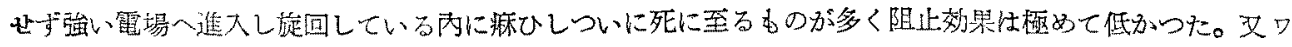

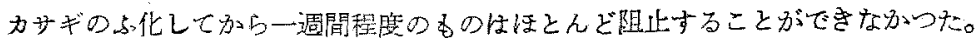

\section{N 結列}

1. 夹際の川，水路等は流下物が多く從来笑施されたすのの使用ざれていない一つの原因が流下物による 
Table 2. Screening Efficiency for Fish.

\begin{tabular}{|c|c|c|c|c|c|c|c|c|c|c|c|c|c|c|c|c|}
\hline \multirow[t]{2}{*}{ Expt.No. } & \multicolumn{3}{|c|}{$\begin{array}{r}\text { Distance bet. Poles } \\
\text { meters }\end{array}$} & \multicolumn{3}{|c|}{$\begin{array}{r}\text { Voltage on the Poles } \\
\text { volt }\end{array}$} & \multicolumn{3}{|c|}{$\begin{array}{r}\text { Potential G adient } \\
\text { at middle of Poles } \\
v / \mathrm{cm}\end{array}$} & \multirow{2}{*}{$\begin{array}{c}\text { Duration } \\
\text { of Expt. } \\
\text { hrs }\end{array}$} & \multicolumn{3}{|c|}{ Fish } & \multirow{2}{*}{$\begin{array}{l}\text { Number } \\
\text { of Fish } \\
\text { passed } \\
\text { the scre- } \\
\text { en }\end{array}$} & \multirow{2}{*}{$\begin{array}{l}\text { Number } \\
\text { of Fish } \\
\text { Electro } \\
\text { cuted }\end{array}$} & \multirow{2}{*}{$\begin{array}{r}\text { Screening } \\
\text { Efficiency } \\
\%\end{array}$} \\
\hline & $L_{1}$ & $L_{z}$ & $L_{2}$ & $V_{1}$ & $V_{2}$ & $V_{3}$ & $v_{1}$ & $v_{2}$ & $v_{3}$ & & Species & $\begin{array}{r}\text { Body } \\
\text { Length } \\
\mathrm{cm}\end{array}$ & Number & & & \\
\hline 1 & 2.0 & 1.2 & 1.0 & 100 & 100 & 180 & 0.15 & 0.17 & 0.51 & 15 & Crucian carp & $7 \sim 13$ & 150 & 14 & 1 & 90 \\
\hline 2 & 2.0 & 1.0 & - & 103 & 103 & - & 0.16 & 0.31 & - & 19 & " & $" \prime$ & 149 & 5 & 3 & 95 \\
\hline 3 & 2.0 & 1.0 & - & 154 & 154 & - & 0.21 & 0.48 & - & 11 & $\prime \prime$ & $" \prime$ & 140 & 23 & 7 & 79 \\
\hline 4 & 2.0 & 1.0 & - & 190 & 190 & - & 0.28 & 0.56 & - & 11 & $" i$ & $\therefore$ & 133 & 15 & 2 & 87 \\
\hline 5 & 2.0 & 1.2 & 1.0 & 150 & 150 & 150 & 0.25 & 0.34 & 0.44 & 9 & $\begin{array}{l}\text { Crucian carp } \\
\text { Carp } \\
\text { Common dace }\end{array}$ & $\begin{array}{r}7 \sim 13 \\
15 \sim 22 \\
16 \sim 20\end{array}$ & $\begin{array}{r}206 \\
10 \\
26\end{array}$ & $\begin{array}{r}30 \\
0 \\
2\end{array}$ & $\begin{array}{l}7 \\
2 \\
2\end{array}$ & $\begin{array}{l}82 \\
80 \\
85\end{array}$ \\
\hline 6 & 2.0 & 1.2 & 1.0 & 108 & 108 & 108 & 0.15 & 0.21 & 0.28 & 11 & $\begin{array}{l}\text { ' } \\
\text { "' } \\
\prime \prime\end{array}$ & $\begin{array}{l}\text { " } \\
1 " \\
1 "\end{array}$ & $\begin{array}{r}168 \\
6 \\
21\end{array}$ & $\begin{array}{r}11 \\
0 \\
0\end{array}$ & $\begin{array}{l}0 \\
0 \\
1\end{array}$ & $\begin{array}{r}93 \\
100 \\
95\end{array}$ \\
\hline 7 & 2.0 & 1.5 & - & 74 & 110 & - & 0.11 & 0.24 & - & 1.3 & $\begin{array}{l}\text { Crucian carp } \\
\text { Carp } \\
\text { Cnmmon dace } \\
\text { Ayu }\end{array}$ & $\begin{array}{r}8 \sim 13 \\
8 \sim 13 \\
13 \sim 18 \\
14 \sim 17\end{array}$ & $\begin{array}{l}50 \\
50 \\
20 \\
30\end{array}$ & $\begin{array}{r}8 \\
10 \\
1 \\
2\end{array}$ & $\begin{array}{r}7 \\
3 \\
3 \\
12\end{array}$ & $\begin{array}{l}70 \\
74 \\
80 \\
53\end{array}$ \\
\hline 8 & 2.0 & 1.5 & - & 60 & 90 & - & 0.08 & 0.20 & - & 20 & $\begin{array}{l}" 1 \\
1 " \\
1 " \\
"\end{array}$ & $\begin{array}{l}\text { "1 } \\
" 1 \\
" 1\end{array}$ & $\begin{array}{l}50 \\
50 \\
20 \\
18\end{array}$ & $\begin{array}{l}1 \\
5 \\
0 \\
2\end{array}$ & $\begin{array}{r}2 \\
4 \\
1 \\
12\end{array}$ & $\begin{array}{l}94 \\
82 \\
95 \\
22\end{array}$ \\
\hline 9 & 2.0 & 1.5 & 1.25 & 13.5 & 21.0 & 33.5 & 0.024 & 0.042 & $|0.100|$ & 25 & Rainbow Trout & $11 \sim 12$ & 205 & 2 & 2 & 98 \\
\hline
\end{tabular}




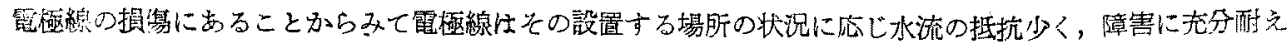
得名夫夫な萝造としなけ机ばならない。

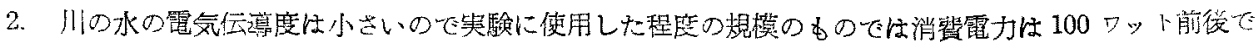

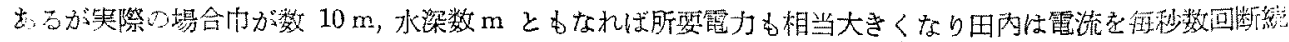

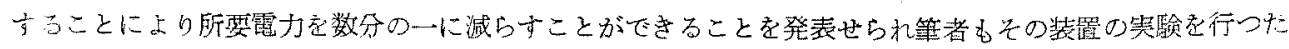

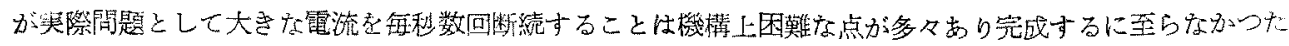

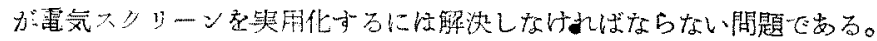

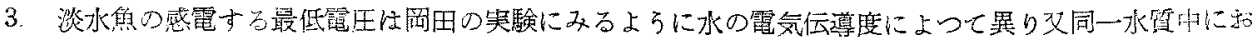

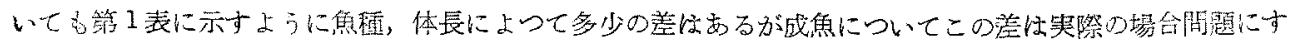

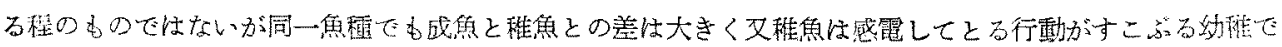

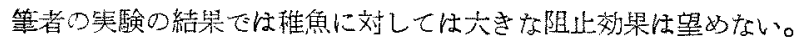

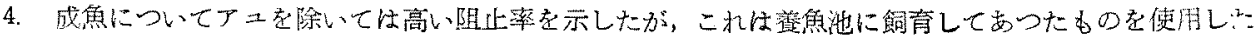
ためで自然の環境にある野性のものについてはこ机程の阻止率は望めないとしても，魚は感電するような好 ましくない場所を避け又との場所を覚えていることから笑際の場合にむ相当な阻止効果があるすのと思水れ Ђ。

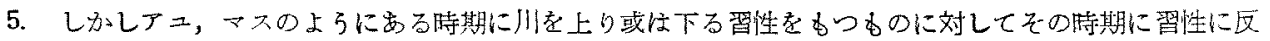
して阻止できるかどらかは残された問題である。

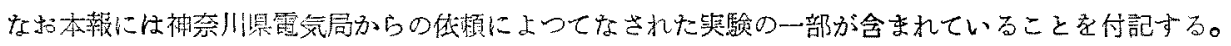

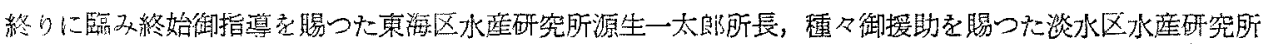

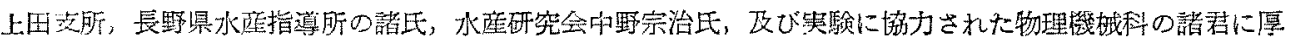
く態謝の意を表する。

\section{交瓶}

1) 岡田：水講報告 $24 ，(2)(1929), 25 ，(1)$ (1930)

2) 田扁：水講報告 27, (1) (2) (1932)

3) 檜山：水産動物の研究 I , (4) (1950)

4) 黑木：日水会誌 16，(4) (1950)

5) 票屋：東京工大研究報告 B，(3) (1951) 